\title{
MEMÓRIA DA COLONIZAÇÃO EM TRADUÇÃO E PERFORMANCE
}

\author{
Eleonora Frenkel Barretto ${ }^{1}$ \\ 1-Universidade Federal de Santa Catarina, Florianópolis, Santa Catarina, Brasil
}

\begin{abstract}
Resumo: O artigo tem o objetivo de analisar a cena inaugural da conquista da América como "ato reiterativo" e suas traduções intersemióticas como conformadoras de um arquivo que o restaura e repete em um presente em constante renovação, constituindo-se as traduções como reperformances dessa cena inaugural e de seus desdobramentos. Ao observar os movimentos que acompanham o momento inaugural da conquista territorial, vem à baila a condenação de práticas incorporadas de indígenas (língua falada e ritos, em particular) e a funcionalidade da tentativa de seu apagamento para efeitos de dominação. $\mathrm{O}$ trabalho de transcrição e tradução de parte do repertório de culturas ameríndias, levado a cabo por missionários como Diego de Landa e Bernardino de Sahagún, discute-se como duplo movimento onde se enfrentam memória e apagamento. Se, por um lado, deixam um registro de memória arquival que permite reconhecer as performances indígenas banidas pelo poder colonial, por outro lado, a concepção monológica da tradução faz prevalecer o objetivo da conversão da cultura de partida, redundando em uma forma de apagamento por sua subjugação aos paradigmas da cultura de chegada.
\end{abstract}

Palavras-chave: Tradução; Performance; Memória; América Latina

\section{COLONIZATION MEMORY IN TRANSLATION AND PERFORMANCE}

\begin{abstract}
The article aims to analyze the inaugural scene of the conquest of America as a "reiterative act" and its intersemiotic translations as conformers of an archive that restores and repeats it in an ever renewed present, constituting the translations as performances of this inaugural scene and of its deployments. By observing the movements that accompany
\end{abstract}


the inaugural moment of territorial conquest, the condemnation of embodied practices of indigenous people (spoken language and rites, in particular) and the attempt to erase them for the purpose of domination comes up. The work of transcription and translation of part of the repertoire of Amerindian cultures, carried out by missionaries such as Diego de Landa and Bernardino de Sahagún, is discussed as a double movement where memory and erasure are confronted. If, on the one hand, they leave a record of archival memory that allows the recognition of indigenous performances banished by the colonial power, on the other hand, the monological conception of translation makes the objective of the conversion of the starting culture prevail resulting in a form of erasure by its subjugation to the paradigms of the arrival culture.

Keywords: Translation; Performance; Memory; Latin America

\section{Performance e tradução da cena inaugural da conquista}

CENA 1: Cristóvão Colombo alça a bandeira real e declara a possessão do território outrora chamado Guanahani e, doravante, San Salvador. Sua cabeça está descoberta e seu chapéu repousa no chão, sinalizando a sacralidade do evento. Os capitães das caravelas o seguem, erguendo os estandartes dos reis católicos. Parte da tripulação, com suas armas em riste, resguarda os líderes e os símbolos, emoldurando o ato que instaura o domínio; outra parte, comemora a chegada em terra firme e alguns a tocam, quiçá anunciando a escavação em busca de ouro. Um dos tripulantes está ajoelhado sobre o chão, ao lado de um indígena, a quem parece lhe apartar a mão da terra, prenunciando a despossessão que lhe seria imposta. Outros indígenas se ocultam atrás de uma árvore e um deles se curva frente aos homens vestidos, em gesto de submissão e veneração. O ano é 1492 . 
Figura 1: John Vanderlyn, Landing of Columbus, 1847. Óleo sobre tela. $365,7 \mathrm{~cm}$ x $548,6 \mathrm{~cm}$

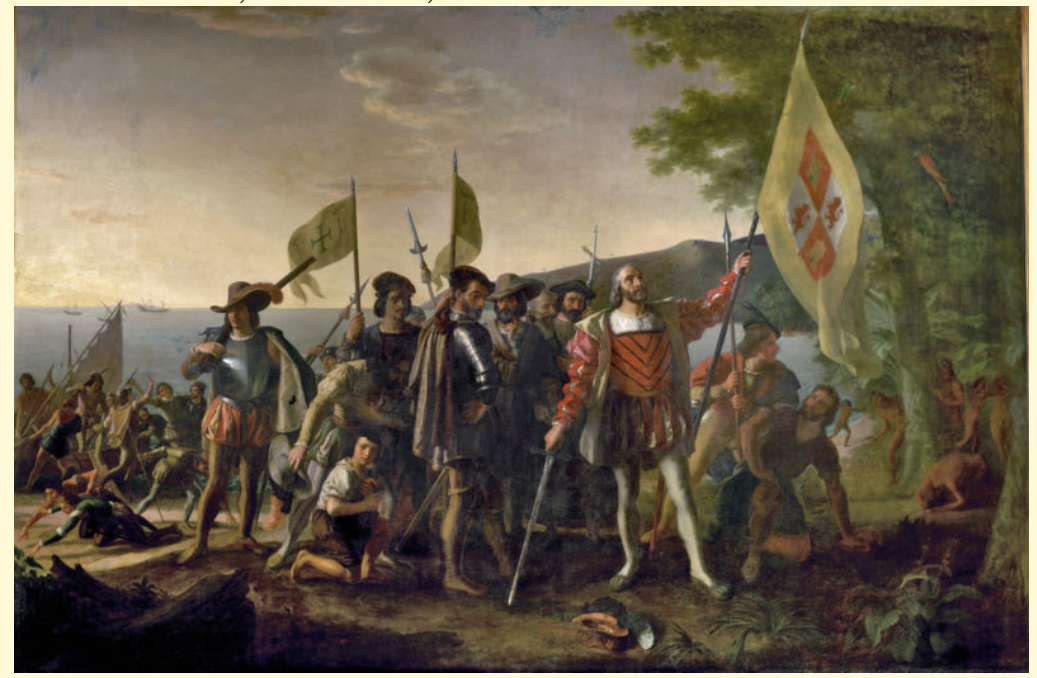

Fonte: Página Architect of the Capitol ${ }^{1}$

CENA 2: Balboa chega aos Mares do Sul. Com os pés nas águas, a espada em punho e o estandarte com o escudo de Castilla y León, de um lado, e a imagem da virgem Maria de outro, o então Marquês e governador de Panamá y Coiba brada que toma posse daquelas terras. Do alto da cordilheira de Chucunaque, de onde os expedicionários avistam o mar, o padre Andres de Vera entoa o Te Deum Laudamus e alguns soldados cortam uma árvore para fazer um grande crucifixo, onde gravam os nomes dos reis católicos, e o fincam com os braços abertos voltados aos dois oceanos. O ano é 1513. Como diz a narrativa de Pereira, "não suspeitavam os infelizes [indígenas ali presentes] que este símbolo de madeira anunciava o fim de sua raça e indicava o caminho da que haveria de se chamar civilização europeia."2 (Pereira 335; tradução minha)

1 Disponível em: https://www.aoc.gov/explore-capitol-campus/art/landingcolumbus (Acesso em: 03/12/2019).

2 "No sospechaban los infelices que este símbolo de madera anunciaba el fin de su raza

Cad. Trad., Florianópolis, v. 40, n 3, p. 34-57, set-dez, 2020. 
Figura 2: Roberto Lewis, Descubrimiento del Mar del Sur, 1924. Pintura mural.

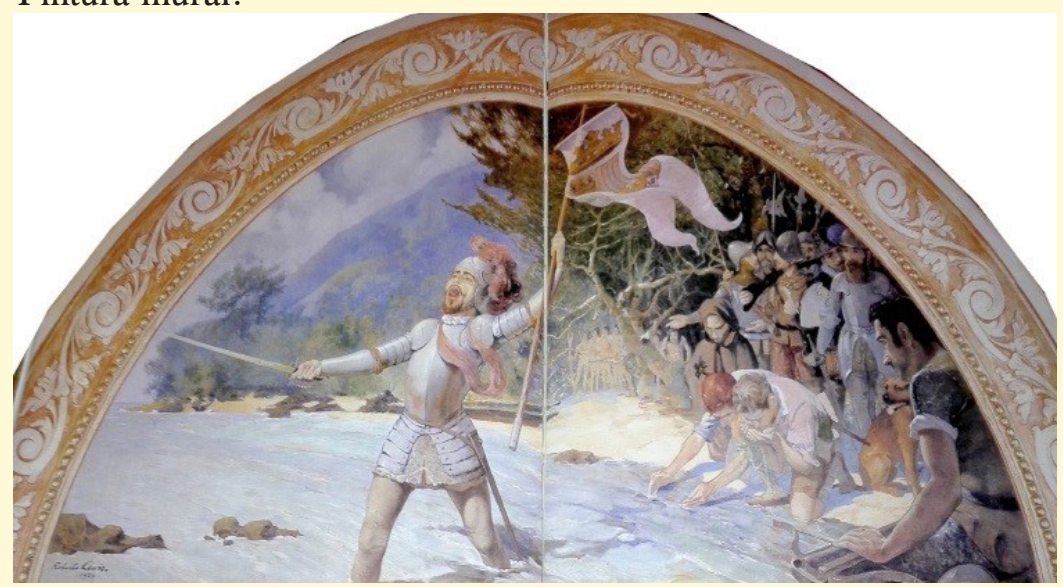

Fonte: Barrios 77.

A cena inaugural da conquista possui um roteiro previsível que será repetido incontáveis vezes; trata-se de uma encenação que envolve personagens, gestos, signos e discursos que se estabelecem como padrão e que instauram o acontecimento. Como "ato reiterativo", a cena inaugural pode ser pensada como uma performance, a partir da análise de Taylor, que diz que:

O roteiro do descobrimento é realmente teatral. Os autoproclamados descobridores performatizam a reivindicação em público ao encenar movimentos específicos (fincar a bandeira) e ao recitar as declarações oficiais em um espetáculo apoiado por sinas visíveis de autoridade (a bandeira real e os estandartes com as letras gravadas). A performance é assistida pelas testemunhas que escreverão sobre ela, 'registrada em detalhes na evidência lá consignada por escrito.' (Taylor (b) 95)

y señalaba el camino de la que había de llamarse civilización europea." (Pereira 335).

Cad. Trad., Florianópolis, v. 40, n 3, p. 34-57, set-dez, 2020. 
Não poucas vezes, a cena inaugural é acompanhada de cruentas batalhas, onde a demonstração do arsenal e dos estratagemas de guerra configura também signos de autoridade.

CENA 3: Em território asteca, em 1520, após a derrota do exército comandado por Cortés no episódio conhecido como La noche triste, este se desloca de Tenochtitlán para Tlaxcala e, no caminho, no vale de Otumba, enfrenta-se a um grande número de guerreiros mexicas que terminam por sucumbir após a derrubada de seu chefe e de seu estandarte de guerra (Tlahuizmatlaxopilli).

Figura 3: Anônimo, Conquista de México: Batalla de Otumba, 1783-1800. Óleo sobre cobre. $66,20 \mathrm{~cm} \mathrm{x} \mathrm{49,30} \mathrm{cm}$

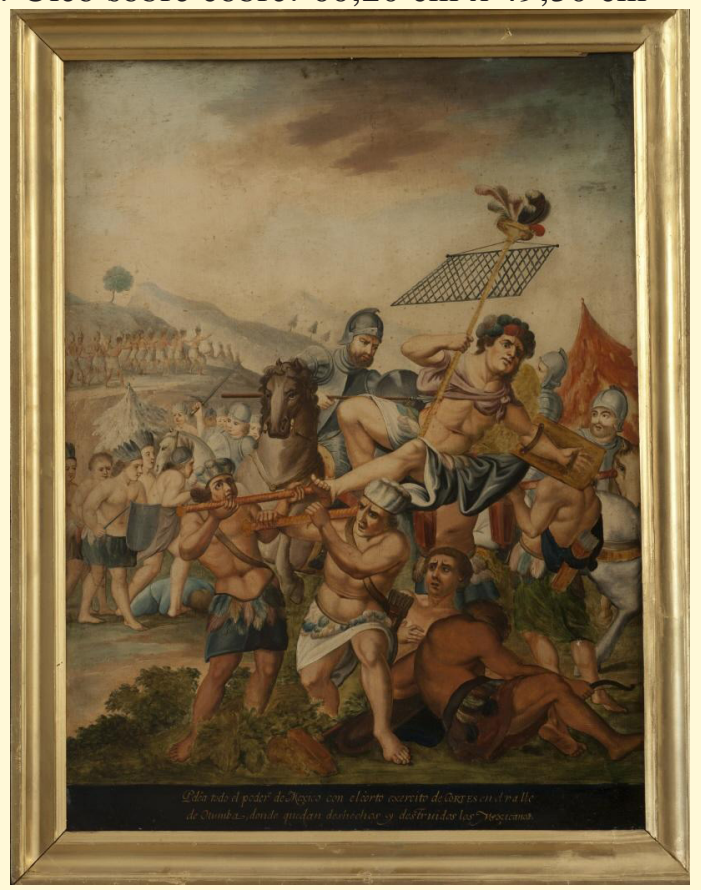

Fonte: Página Red Digital de Colecciones de Museos de España ${ }^{3}$.

3 Disponível em: http://ceres.mcu.es/pages/Main?idt=201\&amp;inventary $=0$ 0215\&amp;table =FMUS\&amp;museum =MAM. (Acesso 03/01/2020).

Cad. Trad., Florianópolis, v. 40, $\mathbf{n}^{0}$ 3, p. 34-57, set-dez, 2020. 
Episódios como esse são narrados em cartas, crônicas, diários e relatos enviados aos soberanos, representando o excelente desempenho $^{4}$ dos exércitos de conquista. Os textos e imagens que repetem o roteiro do descobrimento podem ser pensados como traduções intersemióticas dessa performance inaugural. Segundo Plaza, a partir de sua leitura de Jakobson, uma tradução intersemiótica é a " "tradução de um sistema de signos para outro, por exemplo, da arte verbal para a música, a dança, o cinema ou a pintura', ou vice versa, poderíamos acrescentar." (Plaza xi) Neste caso, pensamos a tradução de uma prática incorporada, a performance da conquista, para um código verbal ou visual, nas diversas textualidades, pinturas e gravuras que a reiteram ao longo de séculos.

Na segunda carta enviada ao rei, em 1520, Cortés relata os sucessos de um dia de batalhas, em Yucatán. Conta que lidera um combate onde queima seis pequenos povoados, prende e leva para um acampamento quatrocentas pessoas, sem que estas lhe façam qualquer dano. No dia seguinte, antes do amanhecer, sai do acampamento com cavalos, peões e índios e queima dez povoados, onde há mais de três mil casas. Registra: "Como trazíamos a bandeira da cruz e lutávamos por nossa fé e por serviços de vossa sacra majestade, em sua real ventura nos deu Deus tanta vitória, posto que matamos muita gente sem que nenhum dos nossos sofresse dano." (Cortés 33)

Na mesma carta, o capitão relata a grandiosidade de cidades como Tlaxcala e Tenochtitlán. Sobre a primeira, dissera ser uma cidade com "bons edifícios com muita gente e melhor abastecida de coisas da terra do que Granada." (Cortés 47) Os adjetivos para descrevê-las são da ordem do maravilhoso e incrível, e toda a riqueza e organização social dos astecas o surpreende: "Considerando ser esta gente bárbara e tão apartada do conhecimento de Deus, é de se admirar ao ver como têm todas as coisas." (Cortés 47) Embora

\footnotetext{
${ }^{4}$ Outra acepção do termo performance largamente utilizado atualmente no campo dos negócios, dos empreendimentos, como o foram as viagens ultramarinas, em busca de metais preciosos e novos espaços de comércio.
}

Cad. Trad., Florianópolis, v. 40, no 3, p. 34-57, set-dez, 2020. 
perceba que "as pessoas andam bem vestidas, com boas maneiras, quase da mesma forma como se vive na Espanha" (Cortés 47), o fugaz encantamento não lhe demove de sua empreitada de conquista e saqueio.

No final do século XVI, o interesse por livros, especialmente os ilustrados, sobre o continente americano é crescente na Europa, sendo exibidos e vendidos em Frankfurt e, posteriormente, Leipzig (Freire 202). A Brevíssima relação da destruição das Índias, de Las Casas, aparece, em 1598, em edição ilustrada por gravuras de Bry. Na época, o texto já era conhecido em algumas regiões do continente e um dos motivos comerciais de sua divulgação se atribui aos interesses de usá-lo como propaganda contra a hegemonia castelhana, principalmente nos Países Baixos, onde havia conflitos com a coroa espanhola desde a abdicação de Carlos V, em 1556 (Freire 202). Las Casas apresenta uma leitura idealizada de ilhas caribenhas, construindo a imagem de um paraíso perdido, de terras férteis habitadas por pessoas inocentes e ingênuas, dóceis cordeiros, muito "aptos a receber" a "santa Fé Católica" (Las Casas 27). A perspectiva do frei desloca a percepção dos ameríndios como praticantes de sacrifícios e atos de canibalismo, o que causava repulsa entre os europeus e contribuía para justificar as práticas de domínio e catequização. Com as descrições de Las Casas, os bárbaros são os espanhóis, que:

Entravam nas vilas, burgos e aldeias, não poupando nem as crianças e os homens velhos, nem as mulheres grávidas e parturientes e lhes abriam o ventre e as faziam em pedaços como se estivessem golpeando cordeiros fechados em seu redil. (Las Casas 31)

A primeira ilustração de Bry na edição da Brevíssima relação... (1598), realiza uma tradução intersemiótica da passagem em que Las Casas conta como os conquistadores: 
Arrancavam os filhos dos seios da mãe e lhes esfregavam a cabeça contra os rochedos enquanto que outros os lançavam à água dos córregos rindo e caçoando [...] Faziam certas forcas longas e baixas, de modo que os pés tocavam quase a terra, um para cada treze, em honra e reverência de Nosso Senhor e de seus doze Apóstolos (como diziam) e deitando-lhes fogo, queimavam vivos todos os que ali estavam presos. (Las Casas 31)

Figura 4: Theodor Dietrich de Bry, ilustração para Brevíssima relação da destruição das Índias, 1589.

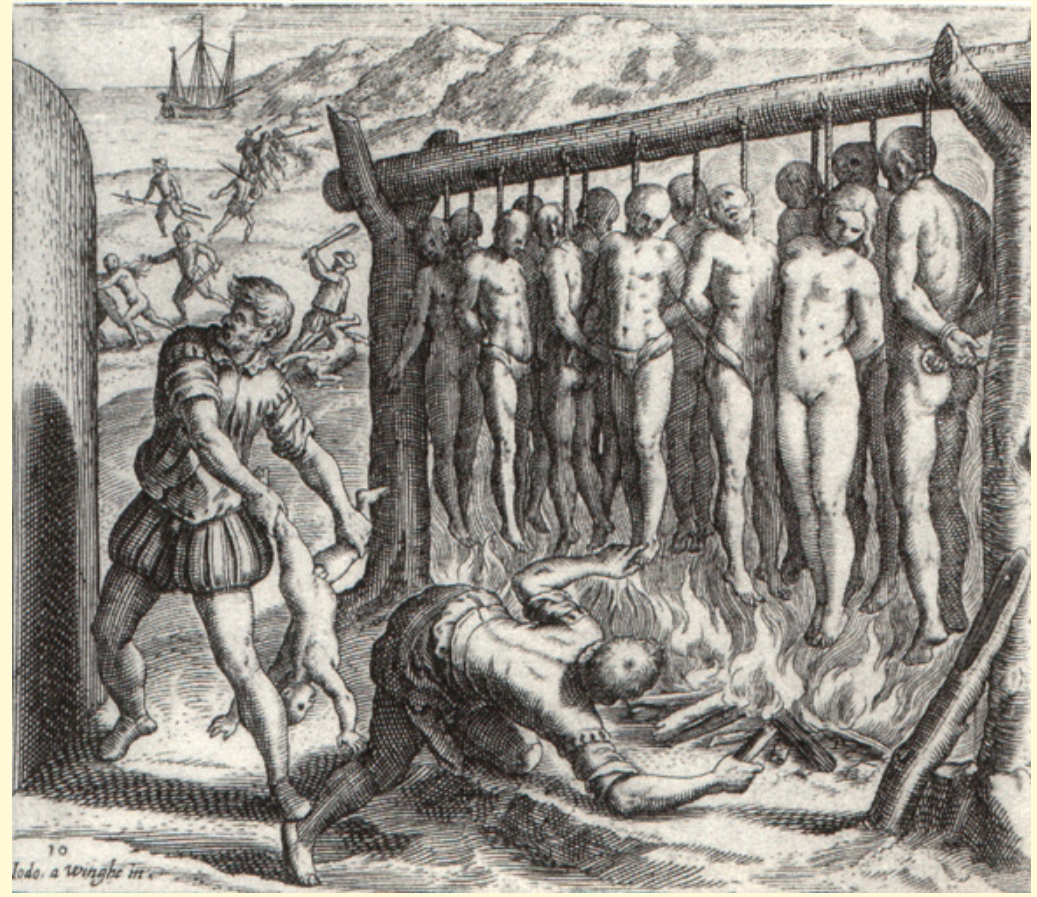

Fonte: Freire 206. 
Como a tradução se realiza como operação de leitura e como criação, ${ }^{5}$ há elementos nessa nova composição que a ressignificam. A imagem lê o texto a partir dos ideais renascentistas de beleza, representando os dorsos nus e a estrutura muscular que remetem à arte de Michelangelo; as feições dos indígenas são europeizadas, as mulheres se parecem a madonas e os homens a Apolos. "A europeização dos indígenas torna-os homens, humanos, descarta a categoria de bárbaros" (Freire 205), o que vem a ser conveniente para alertar algumas regiões europeias sobre os requintes de crueldade de que seriam capazes os espanhóis em terras sob seu poder e, o mais importante, que não o fariam somente contra indígenas (como o fizeram contra mouros ou judeus), mas contra qualquer homem, inclusive brancos e de "boa aparência". Mesmo que indígenas branqueados, a imagem contrasta as posturas e as relações de autoridade: os conquistadores estão vestidos com trajes "pesados e pomposos" (Freire 205), erguem lanças em suas mãos e levam elmos sobre a cabeça, enquanto as indígenas, que parecem de menor porte e estatura, encontram-se nuas, atadas, enforcadas ou golpeadas. A delicadeza e a ternura que Las Casas (27) atribui ao povo que encontra na Ilha Espanhola são acentuadas pelo olhar de um dos enforcados que se eleva para o alto, como pedindo clemência. Ao analisar esse gesto, Freire afirma:

\footnotetext{
${ }^{5}$ Plaza afirma que "leitura, tradução, crítica e análise são operações simultâneas, embutidas e/ou paralelas que serão sintetizadas na tradução.” (Plaza 30) A afirmação se apoia nas reflexões de Haroldo de Campos sobre a tradução como transcriação e nos questionamentos de Walter Benjamin sobre princípios que orientam a busca por uma tradução que se assemelhe ao original (como a noção de fidelidade). Nesse sentido, as operações simultâneas de leitura e crítica também envolvem a criação: “O que já é válido para a tradução poética como forma, acentua-se na tradução intersemiótica. A criação neste tipo de tradução determina escolhas dentro de um sistema de signos que é estranho ao sistema do original. Essas escolhas determinam uma dinâmica na construção da tradução, dinâmica esta que faz surgir a tradução do traduzido, intensificando diferenças entre objetos imediatos. A tradução intersemiótica é, portanto, avessa à ideologia da fidelidade." (Plaza 30)
} 
Sua expressão é de martírio, o que a torna muito eficaz para um olhar cristão, pois se assemelha à representação do martírio dos santos da Igreja católica. Logo, os indígenas, descritos pelo frei como inocentes e ingênuos, são vitimados pela força do opressor sem chance de defesa. A expressão dos indígenas na forca intensifica a imagem daquele que tudo sofre sem se revoltar, nem mesmo com blasfêmias ou expressões odiosas. Ao contrário, a expressão é de resignação ante o castigo. (Freire 207)

Somado ao discurso da exuberância da natureza, a criação da imagem da bondade e resignação dos povos ameríndios abre condições para imaginar novos modelos de colonização que viriam a se suceder, aparentemente menos brutais, ocasionalmente mais inclusivos ou democráticos. Os processos de independência das nações latino-americanas que se propagam ao longo do século XIX reivindicam a autonomia em relação aos impérios até então dominantes, como a Espanha, a essa altura em pleno declínio. Porém, o eurocentrismo não deixa de imperar e se alia também ao norte-americacentrismo. No campo da literatura, a preocupação por criar uma expressão tipicamente nacional, apoiada nas variações do castelhano nas distintas regiões, em personagens e paisagens locais, levou ao interesse pelo indígena, sua língua e costumes, a partir do modelo do romance europeu e, na maior parte das vezes, da perspectiva de homens ou mulheres brancos/as e letrados/as. Como o caso de Turner, em Aves sin nido (1889), que conclama a compaixão pelos pueblos chicos do Peru e a necessidade de melhorar sua condição. ${ }^{6}$ Há aí uma inflexão no modo como as novas elites governantes e as instituições de Estado irão lidar com a subjugação de povos originários e na definição do lugar que lhes será

6 "Llevada por este cariño, he observado durante quince años multitud de episodios que, a realizarse en Suiza, la Provenza o la Saboya, tendrían su cantur, su novelista o su historiador que los inmortalizase con la lira o con la pluma; pero que, en lo apartado de mi patria, apenas alcanzan el descolorido lápiz de una hermana." (Turner 4). 
atribuído nos respectivos projetos de nação, civilização e progresso que se pretendem desenhar.

Na análise de Polar, a narrativa de Turner explicita a excentricidade de seu ponto de vista, o fato de que quem conta a história sobre o/a indígena, não é indígena, assim como não será, primordialmente, o público leitor, o que, segundo Polar, define o indigenismo como literatura heterogênea. Essa primeira conclusão leva-o a realizar a seguinte generalização:

\begin{abstract}
No relato indigenista, como nas crônicas [da conquista], o indígena aparece como matéria de um ato de 'tradução' que o narrador realiza para o leitor, ato pelo qual se assume, por um lado, que o referente foi transferido para outro 'código', e por isso interferido, mas também, por outro lado, que o 'tradutor' é suficientemente capaz e sua 'tradução' suficientemente fiel para oferecer uma imagem certeira da realidade indígena. ${ }^{7}$ (Polar 724; tradução minha)
\end{abstract}

Segundo Polar, o que ocorre nas crônicas da conquista é que

homens de 'outro mundo' empregam seus recursos linguístico-culturais para revelar o que lhes é desconhecido por completo e para torná-lo inteligível frente a leitores distantes, ainda mais alheios a essa realidade nova e insólita. ${ }^{8}$ (Polar 723)

\footnotetext{
7 "En el relato indigenista, como en las crónicas, lo indígena aparece como materia de un acto de 'traducción' que realiza el narrador para el lector, acto por el que se asume, por una parte, que el referente ha sido transferido a otro 'código' , y por eso interferido, pero también, por otra parte, que el 'traductor' es suficientemente capaz y su 'traducción' suficientemente fiel como para ofrecer una imagen certera de la realidad indígena." (Polar 724)

8 "Hombres de 'otro mundo' emplean sus recursos lingüístico-culturales para revelar lo que les es desconocido por completo y para hacerlo inteligible frente a lectores distantes, aún más ajenos a esa realidad nueva e insólita.” (Polar 723)
} 
No romance indigenista, por sua vez, “as camadas médias urbanas aplicam seus atributos culturais [...] e sua ideologia e interesses sociais para interpretar e compreender a natureza de uma realidade outra, a indígena [...] cujo imaginário obedece a outras racionalidades [...]."9 (Polar 722; tradução minha)

A tradução como transferência a outro código, como embarcação que conduz de um porto a outro (como cruzamento de fronteiras), implica a memória daquilo que traduz e, enquanto tal, enquanto história escrita em um presente em constante atualização, ${ }^{10}$ para além de pretensamente ser fiel a uma realidade, o que faz é criar percepções do real. Pela heterogeneidade dos recursos (ou códigos), o que se evidencia é que há um processo de criação, por vezes de recorte e montagem do referente a ser traduzido, que revela que, para além de tornar algo inteligível, apresenta-se algo que se quer performar, no sentido de tornar presente, reiterar e atualizar como prática. Os textos e as imagens que traduzem performances da conquista, para além de informar à Europa o que se passa no "novo" continente, instauram os comportamentos que serão reiterados ao longo de séculos: a postura e a posição (superior e subjugada) de cada um dos personagens em tensão, os objetos e os modos de veneração, as línguas e os ritos.

A submissão não é condição encontrada a priori e sim imposta pelo abuso da força e normalizada pela repetição infinita da cena inaugural nos diversos materiais que compõem o arquivo das culturas latino-americanas. Volta a ser pertinente a assertiva de Walter Benjamin de que "nunca houve um monumento da cultura que não fosse também um monumento da barbárie." (Benjamin 225) A tradução, em sentido amplo (como mediação cultural, interlingual ou intersemiótica), ao ser uma das práticas que contribuem para

\footnotetext{
9 "Las capas medias urbanas aplican sus atributos culturales [...] y su ideología e intereses sociales [...] para interpretar y comprender [...] la naturaleza de una realidad otra, la indígena [...] cuyo imaginario obedece a otras racionalidades." (Polar 722)

${ }^{10}$ Como afirma Benjamin: "A história é objeto de uma construção cujo lugar não é o tempo homogêneo e vazio, mas um tempo saturado de 'agoras'.” (Benjamin 229)
} 
a conformação do repertório e do arquivo $^{11}$ das distintas culturas, apresenta-se, tal qual a memória, como "operação infinita”, como ação jamais completa, sempre por refazer. Seligmann-Silva (213) diz que "a tradução se revela como uma operação infinita - como o é o trabalho da memória que sempre tem que retomar o delicado fio da experiência para tecer a nossa identidade." A singularidade no modo de tecer a identidade concerne ao modo de recepção da alteridade, o modo como coexistem as heterogeneidades ou como se as faz subjugar uma à outra.

\section{Tradução monológica e catequese}

CENA 4: Em um dos grandiosos templos em Tenochtitlán, Cortés percorre as salas que o compõem, onde estão os ídolos principais, e observa sua maravilhosa grandeza, os belos trabalhos em cantaria, madeiramento e figuras esculpidas. Prontamente, derruba de seus assentos os principais ídolos, nos quais os astecas tinham mais fé, e os faz rolar escada abaixo. Em seu lugar, manda colocar a imagem de Nossa Senhora e de outros santos, embora o líder Montezuma e nativos apresentem resistência. Cortés os faz entender quão enganados estavam em ter esperanças naqueles ídolos e que deveriam saber que existe um só Deus,

11 Taylor estabelece uma distinção fundamental entre o repertório, constituído por práticas e conhecimentos incorporados (como língua falada, dança, esportes, ritual), e o arquivo, conformado por materiais supostamente duradouros (como textos, documentos, edifícios, ossos). A conquista do território ameríndio impõe uma desvalorização das práticas incorporadas e uma supervalorização da memória arquival, instituindo a escrita como modo primordial de transmissão e valoração de conhecimento. "A importância dada à escrita aconteceu às custas das práticas incorporadas como modos de conhecimento e de fazer reivindicações. Aqueles que controlavam a escrita - primeiro os frades e, em seguida, os letrados - ganharam poder excessivo." (Taylor (b) 47) 
senhor universal de todos e que é a este que deveriam adorar. ${ }^{12}$ Atrelada à conquista do território vem a catequização, a instrução na doutrina católica, para a qual será fundamental eliminar signos e ritos de outras crenças e cosmogonias.

Quarenta e dois anos após esse gesto de Cortés encontra-se na localidade de Maní, na província de Yucatán, uma caverna com numerosos ídolos ensanguentados, que evidenciavam sacrifícios oferecidos a divindades indígenas. Temeroso da ameaça ao projeto missioneiro e da possível rebelião contra a dominação espanhola, Landa comanda o Auto de Maní, um ato público de caráter inquisitorial que averiguou e julgou ritos considerados idólatras, submetendo indígenas à tortura - alguns têm seus cabelos raspados, outros são açoitados, queimados, enforcados -, outros são condenados ao exílio, aos serviços forçados ou ao pagamento de multas. Durante o Auto de fé, são queimados ídolos, altares, vasilhas e códices maias pré-hispânicos.

\footnotetext{
${ }^{12}$ Episódio narrado por Cortés na segunda carta enviada ao Rei da Espanha, datada e assinada em 30/10/1520: “Os principais destes ídolos e nos quais eles tinham mais fé eu derrubei de seus assentos e os fiz descer escada abaixo. Fiz também com que limpassem aquelas capelas, pois estavam cheias de sangue dos sacrifícios que faziam. Em lugar dos ídolos mandei colocar imagens de Nossa Senhora e de outros santos, apesar da resistência de Montezuma e de outros nativos, por entenderem que as comunidades se levantariam contra mim. Eu os fiz entender quão enganados estavam em ter esperanças naqueles ídolos, e que deveriam saber que existe um só Deus, senhor universal de todos [...] e que a este é que deveriam adorar.” (Cortés 46)
} 
Figura 5: Diego Rivera. "Quema de literatura Maya por la Iglesia Católica”. Pintura Mural. Palácio Nacional, Cidade do México.

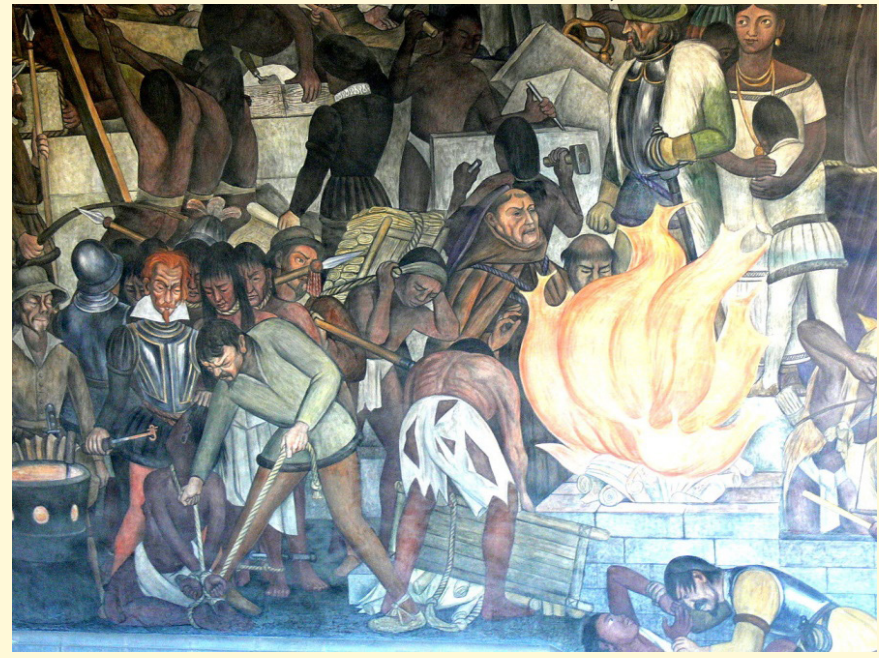

Fonte: Página Pueblos Originarios ${ }^{13}$.

Por outro lado, Landa escreverá a Relación de las cosas de Yucatán (1566), onde apresentará longas descrições a respeito de diversos aspectos da vida dos povos maias, inclusive sua escritura, propondo um código de equivalências de signos hieroglíficos e fonemas do alfabeto latino, como no capítulo XLI, onde traduz: "Ma in Kati quiere decir no quiero y ellos lo escriben por partes de esta manera:

几力 truição causada, o franciscano escreve um texto que será fundamental para o conhecimento da cultura que contribuiu para exterminar, principalmente depois que o manuscrito foi encontrado por Brasseur, traduzido ao francês e publicado em Paris em 1864.

13 Disponível em: https://pueblosoriginarios.com/biografias/landa.html (Acesso 03/01/2020).

Cad. Trad., Florianópolis, v. 40, n 3, p. 34-57, set-dez, 2020. 
A cena inaugural da conquista (com a bandeira da monarquia, a bíblia católica e a declaração de posse) é acompanhada pela violência como espetáculo (em atos públicos de caráter teatral exemplar), pela busca de anulação do repertório da cultura subjugada e a inscrição de um arquivo que a ordene segundo os parâmetros da cultura dominante. Aponta Taylor:

O momento inaugural do colonialismo nas Américas introduz dois movimentos discursivos que contribuem para desvalorizar a performance nativa, mesmo enquanto os colonizadores estavam profundamente empenhados em seu próprio projeto performativo de criar uma 'nova' Espanha a partir de uma imagem (idealizada) da 'antiga': (1) a rejeição das tradições de performance indígenas como episteme; e (2) a rejeição do 'conteúdo' (crença religiosa) como sendo objetos maus de idolatria. (Taylor (b) 68)

A rejeição do amplo repertório de práticas incorporadas de indígenas como formas de conhecimento e o combate às mesmas como idólatras, articulam-se desde os primórdios da conquista com a negação de sua língua. Todorov analisa a reação de Colombo diante dos indígenas que encontra em 1492, quando se recusa a admitir que o que falam seja uma língua. Na carta que escreve aos reis, afirma: "Se Deus assim o quiser, no momento da partida levarei seis deles a Vossas Altezas, para que aprendam a falar" (Colombo apud Todorov 42). Todorov diz que "estes termos chocaram tanto os vários tradutores franceses de Colombo que todos corrigiram: 'para que aprendam nossa língua'." (Todorov 42)

Colombo caíra na grave ilusão analisada por Cassin em relação aos gregos. Segundo a filósofa, estes imaginavam que existia verdadeiramente apenas uma única língua, a sua, que denominavam com a palavra logos; os outros, que não falavam como eles, seriam "bárbaros", os que dizem "blablabla". Logos significa "a língua" e também "a razão", aquela que define o homem e o distingue do animal, como aquele que fala e pensa. "Os gregos falavam o logos, 
ou seja, a língua que constitui a humanidade, a cultura, a racionalidade, de modo tal que não estavam seguros de que os bárbaros fossem homens." ${ }^{14}$ (Cassin 12; tradução minha)

Essa concepção etnocêntrica de não se abrir à escuta da língua e cultura estrangeira e negá-la é reconfigurada ao menos de dois modos no processo de colonização da América: em um caso, quando o sujeito que ouve, compreende o que quer, segundo seu imaginário e suas expectativas; em outro caso, quando o sujeito que ouve, aprende a língua estrangeira e a traduz de modo monológico, a partir de sua própria lógica, visando a anexação e pasteurização da cultura de partida. ${ }^{15}$

Do primeiro caso, o episódio narrado pelo Inca Garcilaso, que teria dado origem ao nome Peru, é um exemplo: capturado por tripulantes de uma embarcação de Balboa que navega pelo Mar do Sul, um indígena que pescava à beira de um rio responde às perguntas que lhe fazem os espanhóis: pelos gestos e acenos que lhe fazem, percebe que está sendo questionado, mas não entende o que lhe perguntam. E ao que ele entende daquilo que lhe é perguntado, responde prontamente, pronunciando seu próprio nome: Berú e acrescenta outro: Pelú. Ele quer dizer: "Se me perguntam como me chamo, meu nome é Berú. E se me perguntam onde estava, digo que estava no rio". Entenda-se que na região onde se encontram, o nome "pelú" significa "rio". (Vega 16) ${ }^{16}$

14 "Los griegos hablaban el logos, es decir la lengua que constituye la humanidad, la cultura, la racionalidad, de modo tal que no estaban seguros de que los bárbaros fueran hombres." (Cassin 12)

15 Seligmann-Silva (210) caracteriza o "fundamentalismo cultural", como algo "nomológico e monológico, ou seja, autolegislador e não-dialógico (ao menos na sua filosofia)", e a ele opõe uma concepção dialógica da tradução, que "é antípoda do modelo da globalização porque este visa apenas a anexação e 'pasteurização' do 'outro'."

${ }^{16}$ Episódio narrado pelo Inca Garcilaso de la Vega, ao qual acrescenta o seguinte comentário: “Denominaram 'Peru' aquele riquíssimo e grande Império, corrompendo ambos os nomes, como corrompem os espanhóis quase todos os vocábulos que tomam daquela linguagem dos índios daquela terra." (Vega 16; tradução minha) ["Llamaron 'Perú' aquel riquísimo y gran imperio, corrompiendo ambos 
Na margem do diário de Colombo, Las Casas anotara: "Estavam todos no escuro, pois não compreendiam o que os índios diziam." (Todorov 43) E o próprio Colombo, desde a ilha Isabela, escreve a suas majestades dizendo que envia "canibais, homens, mulheres, crianças" (Colombo 132) para que possam lhes ensinar a língua e para que se tornem melhores intérpretes. A tradução cultural e interlingual se faz necessária, porém "a dominação depende de manter um olhar unidirecional e encena a falta de reciprocidade e de compreensão mútua inerente ao descobrimento." (Taylor 105) A ética da tradução não é a da diferença e sim a da anexação e conversão. Uma vez admitida a língua do estrangeiro e assumida a humanidade do indígena, a possibilidade de tradução se dá pelo paradigma da intraduzibilidade: "o único modo de acesso a essas culturas é a conversão, a passagem 'total para a outra cultura'”. (Assmann Apud Seligmann-Silva 208).

Sahagún chega ao México em 1529. Para empreender a evangelização, torna-se fluente na língua náhuatl, incorpora-se ao Imperial Colegio de Santa Cruz de Tlatelolco, onde ensina latim aos filhos de nobres indígenas e realiza com grupos de alunos trilíngues um grande estudo dos nahuas do altiplano central. Em 1579, conclui o Códice Florentino, composto por textos em náhuatl, espanhol e escritura pictográfica. Trata-se de um extenso trabalho etnográfico, de entrevistas com anciãos ao longo de anos, transcrições de orações, discursos, canções da tradição oral nahua e sua tradução para o espanhol. Entretanto, há muitas partes do códice que o frei renunciou a traduzir por considerá-las excessivamente idólatras, de linguagem "endiabrada" e obscura (Coronado 119). ${ }^{17}$ Sahagún envia carta ao rei pedindo autorização para tomar medidas rigoro-

nombres, como corrompen los españoles casi todos los vocablos que toman del lenguaje de los índios de aquella tierra." (Vega 16)]

${ }^{17}$ O projeto "Paleografía y traducción del Códice florentino" realiza, desde 2005 , o trabalho de transcrever, paleografar e traduzir os livros que compõem o Códice Florentino. Integram o projeto diversos pesquisadores, principalmente da UNAM, e os resultados são publicados na Revista Estudios de Cultura Náhuatl (http://www.revistas.unam.mx/front/), desde o volume 42 (2011).

Cad. Trad., Florianópolis, v. 40, no 3, p. 34-57, set-dez, 2020. 
sas contra a idolatria, que muitos indígenas seguiam praticando em segredo, mesmo após sua conversão ao catolicismo (Alvim 59). Como afirma León-Portilla, as idolatrias "somente poderiam ser erradicadas quando se conhecessem verdadeiramente as raízes mais ocultas do modo de pensar, crer e viver dos indígenas". (León-Portilla Apud Alvim 54)

É nesse sentido que o modelo de tradução que se estabelece é belicista, pautado no conflito entre as línguas, é colonizador da língua de partida, hostil em relação a ela. ${ }^{18}$ Taylor explicita essa tensão entre a memória e o esquecimento, presente no projeto de Sahagún:

\begin{abstract}
A 'preservação' servia como um chamado para o apagamento. A abordagem etnográfica do assunto oferecia uma estratégia segura para se lidar com materiais perigosos. Ela abria espaço, simultaneamente, para a documentação e o desaparecimento; os relatos preservavam hábitos 'diabólicos' como sendo sempre estranhos e inassimiláveis, transmitindo uma aversão profunda pelos comportamentos descritos. (Taylor (b) 77)
\end{abstract}

As traduções de Sahagún, mesmo com princípios catequizadores, foram alvo de censura e proibição por Felipe II que, em 1577, dirigia ao vice-rei o mandato de recolher o manuscrito do tratado $D e$ la retórica y philosophía moral y Teología de la gente mexicana e

\footnotetext{
${ }^{18}$ Seligmann-Silva analisa a concepção de tradução como Versetzung, de Herder, como dialógica no sentido em que promove o deslocamento do leitor na direção da língua e cultura de partida; porém, as diferenças entre línguas/culturas, embora consideradas, seguem sendo tratadas de modo belicista, subjugando a cultura de partida à de chegada, de modo semelhante à noção de tradução como belle infidèle. "Esta última, que era praticada nos séculox XVII e XVIII (mas também em nossos dias), é 'colonizadora' da língua de partida. Ela submete o 'outro' à lei da casa, do anfitrião. Ela é anti-hospitaleira. Segue a lei da hostilidade e não da hospitalidade." (Seligmann-Silva 209)
} 
enviá-lo ao Consejo de Indias. O mandato adverte que não se deve "consentir que por nenhuma maneira pessoa alguma escreva coisas que toquem a superstições e modos de viver que estes índios tinham, em nenhuma língua". ${ }^{19}$ (Códice Franciscano Apud Coronado 121) Os mandatos de proibição do uso de línguas indígenas se sucedem ao longo do período colonial. Em 1770, o rei Carlos III ordena a interdição do uso de qualquer idioma indígena, a fim de extingui-los e impor o monolinguismo castelhano nas colônias espanholas. ${ }^{20}$

No ano de 1780 , tem lugar nas Províncias do Peru a rebelião indígena liderada pelo cacique do povo Tungasuga. Uma vez vencida a rebelião, Areche pronuncia a sentença contra o líder, sua companheira, seus filhos e demais réus principais: Tupac-Amaru deverá assistir a execução em praça pública de seus familiares condenados; posteriormente, terá sua língua cortada pelo verdugo e será amarrado pelas pernas e braços às cilhas de quatro cavalos, para que estes, incitados ao movimento, possam esquartejar seu corpo. Feito isso, o torso seria levada à altura do monte chamado Picchu, para ser queimado e suas cinzas lançadas ao vento. No lugar da fogueira, será erigida uma lápide de pedra, com o registro

19 "Estaréis advertido de no consentir que por ninguna manera persona alguna escriba cosas que toquen a supersticiones y manera de vivir que estos indios tenían, en ninguna lengua, porque así conviene al servicio de Dios Nuestro Señor y nuestro (Códice Franciscano 1941: 249-50)." (Coronado 121)

${ }^{20} \mathrm{O}$ decreto de Carlos III reafirma a lei de instrução dos indígenas nos "dogmas de nossa religião em castelhano" ("Dogmas de nuestra Religión en Castellano"), devendo este tornar-se o único idioma falado nos territórios sob domínio espanhol: "Para que finalmente se chegue a conseguir que se extingam os diferentes idiomas, de que se faz uso nos mesmos domínios, e somente se fale o Castelhano, como está determinado por repetidas Leis Reais Cédulas. [...] A fim de conseguir a expatriação dos diferentes idiomas que se usam naqueles domínios e somente se fale o castelhano." (Carlos III; tradução minha) "Para que de una vez se llegue a conseguir el que se extingan los diferentes idiomas, de que se usa en los mismos dominios, y solo se hable el Castellano como está mandado por repetidas Leyes Reales Cedulas. [...] A fin de conseguir que se destierren los diferentes Idiomas que se usa en aquellos Dominios, y solo se hable el Castellano". (Real Cédula de Carlos III) Acesso: 10/12/2012 http://www.javierortiz.net/ant/humor/ HUMOR50.HTM. 
escrito de seus principais delitos. Cabeça e membros seriam levados a distintos povoados para serem exibidos. A sentença dita que sejam queimados os registros que tratam de sua descendência, para que não reste memória documental. Para o mesmo fim de eliminar rastros de memória, proíbem-se aos indígenas os usos de trajes tradicionais, especialmente os que denotam nobreza. Foram proibidas as apresentações de encenações públicas que os indígenas costumavam usar para reviver a memória de seus ancestrais e igualmente proibidos seus instrumentos musicais e a assinatura com o nome Inca. Areche sentencia que se intensifique o ensino da língua castelhana, impondo penas mais rigorosas para quem não a use. ${ }^{21}$

Insisto na contextualização da imposição da unicidade da língua hegemônica e da interdição do pluralismo cultural expresso na diversidade de práticas incorporadas de povos ameríndios, para que se possa explicitar o quão profundamente enraizada na história colonial da América está a violência simbólica exercida contra esses povos. A memória da América Latina se configura a partir dos traumas desse processo colonizador. O trauma, assim como a performance, dirá Taylor ((a) 7), “é sempre presente”. E para a memória, afirma Seligmann-Silva (212), "existem traços/imagens do passado que povoam o nosso presente." Nesse sentido, não surpreende que o neocolonianismo do século XXI reencene a performance da conquista. Mas há que se seguir performando, traduzindo e transcriando desde uma perspectiva anticolonial, como a arte da performance que ativa estratégias banidas nas Américas, tais como ritos, cantos, danças; escrituras plurilíngues que fazem sentir e

${ }^{21}$ Lê-se na sentença: "E para que estes índios se desfaçam do ódio que criaram contra os espanhóis, usem os trajes indicados pelas leis, vistam-se de nossos costumes espanhóis e falem a língua castelhana, será introduzido com maior vigor do que até aqui se tem feito o uso de suas escolas, ficando submetidos a penas mais rigorosas e justas aqueles que não as usem." (Areche; tradução minha) "Y para que estos indios se despeguen del odio que han concebido contra los españoles, y sigan los trajes que les señalan las leyes, se vistan de nuestras costumbres españolas, y hablen la lengua castellana, se introducirá con más vigor que hasta aquí el uso de sus escuelas bajo las penas más rigorosas y justas contra los que no las usen." (Areche)

Cad. Trad., Florianópolis, v. 40, no 3, p. 34-57, set-dez, 2020. 
experimentar as diferenças entre as línguas, sem a subjugação ao pensamento etnocêntrico; traduções antimiméticas e dialógicas que apontam para a negação da imitação servil da cultura da metrópole e para a abertura a uma construção coletiva da memória.

\section{Referências}

Alvim, Márcia Helena. "Um franciscano no novo mundo: frei Bernardino de Sahagún e sua Historia General de las Cosas de Nueva España". Estudos Ibero-Americanos. XXXI. 1 (2005): 51-60. Portal de Periódicos da PUCRS. DOI: https://doi.org/10.15448/1980-864X.2005.1.1325 2/12/2019. Disponível em: https://revistaseletronicas.pucrs.br/ojs/index.php/iberoamericana/article/ view/1325.

Areche, José Antonio. "Sentencia pronunciada en el Cuzco por el visitador don José Antonio de Areche, contra José Gabriel Tupac-Amaru, su mujer, hijos, y demás reos principales de la sublevación". Relación histórica de los sucesos de la rebelión de José Gabriel Tupac-Amaru, en las provincias del Perú, el año de 1780, Buenos Aires: Imprenta del Estato, 1836, s.p. cervantesvirtual.com. 2/12/2019. Disponível em: http://www.cervantesvirtual.com/obra-visor/relacion-historicade-los-sucesos-de-la-rebelion-de-jose-gabriel-tupacamaru-en-las-provincias-delperu-el-ano-de-1780--0/html/ff9844fe-82b1-11df-acc7-002185ce6064_3.html.

Benjamin, Walter. Magia e técnica, arte e política. Tradução de Sérgio P. Rouanet. São Paulo: Brasiliense, 1994.

Cassin, Barbara. Más de una lengua. Tradução de Vera Waksman. Buenos Aires: Fondo de Cultura Económica, 2014.

Coronado, Tomás Serrano. "El silencio del traductor". Mutatis Mutandi. 6. 1 (2013): 113-125. Dialnet. 02/12/2019. Disponível em: https://revistas.udea.edu. co/index.php/mutatismutandis/article/view/15051. 
Cortés, Hernán. A conquista do México. Tradução de Jurandir S. dos Santos. Porto Alegre: L\&PM, 1986.

Freire, Deolinda de Jesus. "Theodor de Bry e a narrativa visual da Brevíssima relación de la destrucción de las Indias”. Revista USP. 77. Mar-Mai (2008): 200215. 02/12/2019. DOI: https://doi.org/10.11606/issn.2316-9036.v0i77p200-215. Disponível em: http://www.revistas.usp.br/revusp/article/view/13668.

Landa, Diego de. Relación de las cosas de Yucatán. Paris: Arthus Bertrand Éditeur, 1864. pueblosoriginarios.com. 1/12/2019. Disponível em: https:// pueblosoriginarios.com/textos/landa/1.html.

Las Casas, Frei Bartolmé de. O paraíso destruído. A sangrenta história da conquista da América Espanhola. Tradução de Heraldo Barbuy. Porto Alegre: L\&PM, 2001.

León-Portilla, Miguel. Bernardino de Sahagún. Madri: Quórum, 1987.

Pereira, Octávio Méndez. Núñez de Balboa. Panamá: Prisa Ediciones, 2013. 28/11/2019. Disponível em: https://aplengua.org.pa/wp-content/uploads/2017/04/ N\%C3\%BA\%C3\%B1ez-de-Balboa-de-Octavio-M\%C3\%A9ndez-Pereira.pdf.

Plaza, Julio. Tradução intersemiótica. São Paulo: Perspectiva, 2003.

Polar, Antonio Cornejo. "El indigenismo andino". América Latina: palavra, literatura e cultura, organizado por Ana Pizarro, São Paulo: Memorial, 1994, pp. 720-738.

Sahagún, Frey Bernardino de. Historia General de las cosas de Nueva España. Madri: Alianza, 1988.

Seligmann-Silva. O local da diferença. Ensaios sobre memória, arte, literatura e tradução. 2a . Edição. São Paulo: Editora 34, 2018.

Taylor, Diana (a). "O trauma como performance de longa duração". Tradução de Giselle Ruiz. O percevejo. 1.1. Jan-Jun (2009): 1-12. Portal de Periódicos da UNIRIO. 9/12/2019. DOI: http://dx.doi.org/10.9789/2176- 
7017.2009.v1i1.\%25p. Disponível em: http://www.seer.unirio.br/index.php/ opercevejoonline/article/view/512.

Taylor, Diana (b). O arquivo e o repertório. Performance e memória cultural nas Américas. Tradução de Eliana L. de L. Reis. Belo Horizonte: Editora UFMG, 2013.

Todorov, Tzvetan. A conquista da América: a questão do outro. Tradução de Beatriz Perrone Moisés. São Paulo: Martins Fontes, 2010.

Turner, Clorinda Matto de. Aves sin nido. Caracas: Ayacucho, 1994.

Vega, Inca Garcilaso de la. Comentarios reales de los Incas. Tomo 1. México: Fondo de Cultura Económica, 1991.

Recebido em: 06/03/2020

Aceito em: 10/06/2020

Publicado em setembro de 2020

Eleonora Frenkel Barretto. E-mail: eleonora.frenkel@gmail.com. ORCID: https://orcid.org/0000-0002-3279-2546. 